\title{
Article \\ Preparation of a Photosensitive Composite Carbon Fiber for Spilled Oil Cleaning
}

\author{
Yong X. Gan *(1), Ali Arjan and Jimmy Yik
}

check for updates

Citation: Gan, Y.X.; Arjan, A.; Yik, J. Preparation of a Photosensitive Composite Carbon Fiber for Spilled Oil Cleaning. J. Compos. Sci. 2022, 6, 28. https://doi.org/10.3390/ jcs6010028

Academic Editor: Francesco Tornabene

Received: 8 December 2021 Accepted: 11 January 2022 Published: 12 January 2022

Publisher's Note: MDPI stays neutral with regard to jurisdictional claims in published maps and institutional affiliations.

Copyright: (C) 2022 by the authors. Licensee MDPI, Basel, Switzerland. This article is an open access article distributed under the terms and conditions of the Creative Commons Attribution (CC BY) license (https:// creativecommons.org/licenses/by/ $4.0 /)$.

\author{
Department of Mechanical Engineering, California State Polytechnic University Pomona, 3801 W Temple Avenue \\ Pomona, CA 91768, USA; aarjan@cpp.edu (A.A.); jyik@cpp.edu (J.Y.) \\ * Correspondence: yxgan@cpp.edu; Tel.: +1-909-869-2388
}

\begin{abstract}
This paper deals with preparing a functional composite carbon fiber with a large surface area for spilled oil cleaning. The composite fiber consisted of photosensitive oxide particles and polymer-derived carbon. It was made by co-spinning the polymer and metallic compounds. After heat treatment at high temperatures, an activated carbon fiber containing oxide particles was obtained. The particles were found distributed in the fiber and at the surface of the fiber. The composite fiber was found sensitive to sunlight. Fiber mats made of the composite fiber possessed a high surface area for oil absorption and removal. Cobalt(II) titanate particles were obtained from the reaction of titanium dioxide and cobalt oxide. The reaction happened in situ through the hydrolysis of metallic compounds in the spun fiber. The titanium dioxide and cobalt(II) titanate particle-containing fibers demonstrated the photoactivity in the visible light spectrum. It was concluded that particle-containing composite carbon fiber mats can be prepared successfully by co-electrospinning. Due to the oleophilic property and the high active surface area, the composites are suitable for spilled oil cleaning through fast absorption.
\end{abstract}

Keywords: composite carbon fiber; titanium dioxide particle; cobalt(II) titanate particle; co-electrospinning; carbonization; spilled oil cleaning

\section{Introduction}

The increasing pollution by spilled oil on open water has been one of the driving forces for investigating the oil cleaning technologies. The photocatalytic decomposition of organics by harvesting visible-light-spectrum energy provides a unique way to control the oil spilling pollution [1-4]. Hydrothermally synthesized iron containing titanium dioxide was studies for the photocatalytic decomposition of fractionated crude oil [1]. Song et al. [4] investigated the sunlight-driven self-cleaning property of $\mathrm{BiVO}_{4}$ for the oil/water separation. It was found that the $\mathrm{BiVO}_{4}$ coating on an underwater mesh is effective in the separation of oil/water mixtures. Recently, Li et al. [3] coated hierarchical $\mathrm{Bi}_{2} \mathrm{WO}_{6} @ \mathrm{CuO}$ nanostructures onto the surface of a copper mesh through a combined chemical oxidation and hydrothermal deposition process. The coated copper mesh was found to have a high photocatalytic oxidation capability, so that underwater oily contaminants can be cleaned. The mesh can be deployed with repeated usage for spilled oil cleaning.

Due to the low cost and biodegradable behavior, organic cellulose and cellulose acetate nanofibers have been used for oil cleaning for a long time. For example, a multifunctional deacetylated cellulose acetate nanofiber was made via electrospinning followed by deacetylation [5]. The obtained nanofiber is oleophobic in water, which makes it suitable for water removal from oil/water mixtures. In order to make cellulose nanofiber oleophilic, Chu et al. [6] used hydrophobic polydimethylsiloxane to modify the surface of cellulose nanofibers derived from delignified porous wood. The adsorbent made from the surface-modified-cellulose fiber has a superior oil-retention capability. Hybrid sol-gel electrospinning silica-cellulose diacetate-based nanofibers were demonstrated in [7]. The 
superhydrophobic and high oleophilic nature of the nanofiber allows it to be useful for oil spill cleaning. Jeddi et al. [8] prepared cellulose nanofiber aerogels from waste boxboards in a freeze-drying process. The oil absorption efficiency of the aerogel beads is up to $279 \mathrm{~g} / \mathrm{g}$. They are also highly selective in absorbing oil from oil/water mixtures.

Synthetic polymer fibers are also widely researched for oil spill cleaning. Polystyrene is one of such examples. Li et al. [9] prepared a polystyrene-coated mesh by electrospinning. Since the polystyrene polymer is superhydrophobic, a device made by using the mesh can remove both heavy and light oils from water with a separation efficiency of up to 99.92\% under harsh conditions including in hot water containing salt, strong acids, or bases. In the work performed by Parangusan et al. [10], the electrospun polystyrene nanofiber was reinforced by $0.5 \mathrm{wt} \%$ carbon nanotube. It was reported that the gamma radiation could promote crosslinking and improve the bonding between the polymer and the carbon nanotube filler. The selective oil absorption property has been achieved.

The development of renewable, sensitive photocatalysts with a high specific activated surface area for the adsorption and decomposition of spilled oil in gulf, harbor, lakes, and surface soils has been an active research field. Due to their high surface areas, nanofibers have been proposed as effective photocatalysts for the decomposition of organics and/or clean energy generation. Inorganic nanofibers, including spun $\mathrm{ZnO}$ nanofibers [11], in situ spun $\mathrm{TiO}_{2} / \mathrm{CdS}$ hybrid nanofibers [12], hydrothermally synthesized $\mathrm{Bi} @ \mathrm{Bi}_{2} \mathrm{Sn}_{2} \mathrm{O}_{7} / \mathrm{TiO}_{2}$ plasmonic composite fibers [13], noble metal particle-containing carbon nanofibers [14], and $\mathrm{SrTiO}_{3} @ \mathrm{Mo}_{2} \mathrm{C}$ core-shell nanofibers [15], are some of good examples. In addition, organic nanofibers [16-19] were also studied for the photocatalysis of decomposing dyes and waste organics. Nanofiber materials have the advantages of high absorptivity and enhanced photon sensitivity. Although some previous studies on $\mathrm{TiO}_{2}$-based nanoparticles [20] and nanofibers [21] were reported as high-performance photocatalysts, there are some problems to be resolved. First, $\mathrm{TiO}_{2}$ has a wide energy bandgap. Thus, the light absorption band of $\mathrm{TiO}_{2}$ falls into the ultraviolet (UV) spectrum range. As a result, pure $\mathrm{TiO}_{2}$ nanomaterials cannot use the majority part of the energy from the sunlight properly. Doping $\mathrm{TiO}_{2}$ nanostructures with various metals have been considered to resolve this issue [22]. However, those metals are either very expensive (such as $\mathrm{Pt}, \mathrm{Ni}, \mathrm{Au}$, and $\mathrm{Ag}$ ) or poisonous (e.g., $\mathrm{Cu}, \mathrm{Cr}, \mathrm{Co}$, and $\mathrm{Zn}$ ), which limits the application of metal-doped $\mathrm{TiO}_{2}$. Another issue is that $\mathrm{TiO}_{2}$ has the hydrophilic property. Hydrophobic oil is hard to attach to it, which hinders the adsorption of spilled oil onto the surface of $\mathrm{TiO}_{2}$ nanostructures. To tackle these problems, a partially carbonized nanofiber was made as the continuous phase to hold $\mathrm{TiO}_{2}$ nanoparticles using the reaction electrospinning technique, as shown in an earlier work [23]. $\mathrm{TiO}_{2}$ nanoparticles are incorporated into spun nanofibers through in situ chemical reactions. After that, high-temperature heat treatment in a nitrogen atmosphere is conducted to convert the spun fibers into carbon nanofibers, and the $\mathrm{TiO}_{2}$ nanoparticles are doped with both carbon and nitrogen for visible light absorption. The polymeric carbon nanofibers with a strong hydrophobic behavior attract drops and traces of spilled oil and build up the contact between the absorbed oil and the incorporated $\mathrm{TiO}_{2}$ nanoparticles. Under visible light illumination, the oil drops can be removed effectively by the $\mathrm{TiO}_{2}$ nanoparticles.

\section{Materials and Experimental}

\subsection{Materials and Instruments}

Dimethylformamide (DMF) and titanium(IV) isopropoxide (95\%) were purchased from Alfa Aesar, Ward Hills, MA, USA. A stainless-steel injection needle, purchased from McMaster-Carr, Santa Fe Springs, CA, USA, was used as the spinneret for the electrospinning. The needle had a gage size of 20 with an outer tube diameter of $0.9016 \mathrm{~mm}$. Polyacrylonitrile (PAN) polymer with a molecular weight of 150,000 Da was bought from Scientific Polymer Products, Inc., Ontario, NY, USA. Other chemicals including DMF and cobalt(II) acetate tetrahydrate (all in the ACS purity) were ordered from Alfa Aesar, Ward Hills, MA, USA. A high-voltage direct-current power source was manufactured by Spell- 
man, Inc. Hauppauge, NY, USA. A Fusion 200 precision syringe pump made by Chemyx, Inc., Stafford, TX, USA was used to inject the polymer solution containing the titanium and cobalt compounds during electrospinning. A model OTF-1200X-S-NT-LD compact split tube furnace with a single heating zone, and a programmable controller, made by MTI Corp in Richmond, CA, USA, was used for the oxidization and carbonization of the polymer fiber. A model $\mathrm{CHI}-440 \mathrm{C}$ electrochemical workstation, made by $\mathrm{CH}$ Instrument in Austin, TX, USA, was used to test the photoelectric property of the composite carbon fiber.

\subsection{Compoaite Carbon Fiber Preparation}

The preparation of a highly adsorptive composite material, based on titanium dioxide particles embedded into a partially carbonized fiber from a precursor-PAN polymer-was performed. The titanium dioxide was automatically doped with carbon, $\mathrm{Co}$, and nitrogen during the carbonization process. The adsorption and decomposition of the spilled oil by this composite carbon fiber were characterized. Since the partially carbonized fiber was hydrophobic or oleophilic, the fiber showed a strong oil adsorption behavior and attracted the oil to a short distance from the titanium dioxide. The $\mathrm{C}$ and $\mathrm{N}$-doped titanium dioxide were highly sensitive to both UV and visible light, as also reported in [21,24]. This allowed the adsorbed oil molecules to decompose under the illumination of visible light. The approaches and performed research tasks can be described as follows. $\mathrm{TiO}_{2}$ particle-containing carbon fibers were prepared via reaction spinning first. Doping the particles was carried out through the high-temperature treatment in a nitrogen-containing atmosphere. Then, the composite carbon fibers were held by a glass slide or aluminum plate to form an oil-absorption test specimen. Structure assessment was performed using SEM. The spilled oil absorption test was conducted by inserting it into to water-oil mixtures with different water-to-oil ratios. The oil adsorption kinetics of the composite nanofibers was investigated as well.

PAN with an approximate molecular weight of 150,000 Da was used as the carbon fiber precursor. DMF was used as the solvent to dissolve PAN, so that a $10 \mathrm{wt} \%$ precursor solution was made. Titanium(IV) isopropoxide (95\%) was used as the titanium dioxide source. The formula weight of titanium(IV) isopropoxide was 288.25 . The concentration of titanium(IV) isopropoxide in the DMF solution was about $0.3 \mathrm{wt} \%$. For cobalt(II) titanate particle formation, the concentration of cobalt(II) acetate tetrahydrate in the DMF solution was $0.25 \mathrm{wt} \%$. It is noted that the formula weight of cobalt(II) acetate tetrahydrate was 249.08. The above concentrations for titanium(IV) isopropoxide and cobalt(II) acetate tetrahydrate were selected with the intend to keep the atomic ratio of Ti and Co close to 1:1, so that a stoichiometric compound cobalt may be generated through the annealing. For the co-electrospinning, a high-voltage direct-current power source was set up. As shown by the sketch in Figure 1a, a precision syringe pump was used for polymer fluid injection, and a power source was applied for electrifying the fluid. The waveform of the power supply is shown in Figure $1 b$.

Electrohydrodynamic casting or electrospinning was the process that was used to fabricate the composite fiber in the experiment. The method has the advantage of easy deposition and is versatile in the manufacture of polymeric materials, composites, and ceramics. This process provides a sufficient electrostatic force by applying the varying voltage between the solution and the collector, as shown in Figure 1b, to overcome the surface tension of the solution containing PAN polymer, cobalt(II) acetate tetrahydrate, and titanium isopropoxide. This approach allowed the titanium oxide particle-generating solution and the PAN solution to be co-spun or co-cast onto the collector. As a result, a composite fiber was obtained in the reaction spinning process.

The main reaction during the electrospinning was the titanium dioxide particle formation. The moisture in the air triggered the following hydrolysis reaction [25]:

$$
\mathrm{Ti}-\left[\mathrm{OCH}\left(\mathrm{CH}_{3}\right)_{2}\right]_{4}+2 \mathrm{H}_{2} \mathrm{O} \rightarrow \mathrm{TiO}_{2}(\mathrm{~s}) \downarrow+4\left(\mathrm{CH}_{3}\right)_{2} \mathrm{CHOH}(\mathrm{g}) \uparrow .
$$



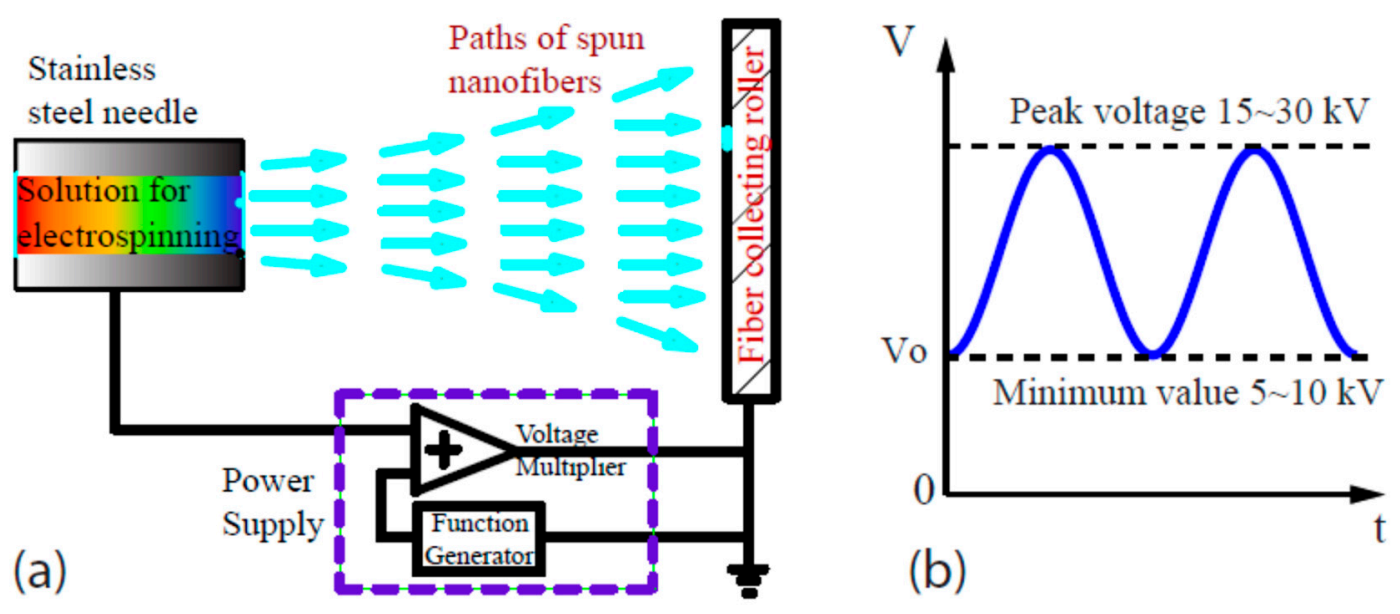

(b)

Figure 1. Schematic drawings: (a) nanofiber spinning set-up; (b) output voltage vs. time.

For the cobalt-containing compound formation, the chemical reactions were shown as following:

$$
\begin{gathered}
\mathrm{Co}-\left[\mathrm{OOC}-\mathrm{CH}_{3}\right]_{2} \cdot 4 \mathrm{H}_{2} \mathrm{O} \rightarrow \mathrm{CoO}(\mathrm{s}) \downarrow+3 \mathrm{H}_{2} \mathrm{O}(\mathrm{g}) \uparrow+2 \mathrm{CH}_{3} \mathrm{COOH}(\mathrm{g}) \uparrow, \\
\mathrm{CoO}(\mathrm{s})+\mathrm{TiO}_{2}(\mathrm{~s}) \rightarrow \mathrm{CoTiO}_{3}(\mathrm{~s}) .
\end{gathered}
$$

Equation (2a) represents the decomposition of cobalt acetate tetrahydrate, and Equation (2b) stands for the cobalt(II) titanate $\left(\mathrm{CoTiO}_{3}\right)$ formation within the carbon nanofiber during annealing. Due to the concentration variation of both titanium isopropoxide and cobalt acetate tetrahydrate in the co-electrospinning process, the generated cobalt(II) titanate $\left(\mathrm{CoTiO}_{3}\right)$ may not be exact in the stoichiometric equation in view of the atomic ratio of Co to Ti. Besides that, the content of the oxygen element can be tuned, depending on the heat treatment temperature and the atmosphere (e.g., hydrogen concentration) in the furnace. Typically, with the increasing in the hydrogen concentration in the atmosphere, the oxygen deficiency can increase the defect concentration due to the fact that the heat treatment and the electrical conductivity of the synthesized cobalt(II) titanate $\left(\mathrm{CoTiO}_{3}\right)$ could be higher.

A compact split tube furnace, as shown in Figure 2a, was used for heat-treating the composite nanofiber. Figure $2 \mathrm{~b}$ shows the gas control instrument. The heat treatment on the fabricated nanofiber caused the oxidation of PAN, and the evaporation of ethanol gas generated from the titanium dioxide formation, as shown in Equation (1), can be completed by setting the specimen into the quartz tube furnace (Figure 2a) and heated to above $250^{\circ} \mathrm{C}$ for $2 \mathrm{~h}$. The air in the quartz furnace was replaced by nitrogen and hydrogen $(10: 1, v / v)$, after the heating temperature reached $500{ }^{\circ} \mathrm{C}$. A continued heating process took an additional $2 \mathrm{~h}$ before cooling down. At such a high temperature in an atmosphere containing both nitrogen and hydrogen $(10: 1, v / v)$, the PAN fiber was converted into a partially carbonized one. In addition, the titanium dioxide was forced crystalized and doped with $\mathrm{N}$ and $\mathrm{C}$ [26]. Chen et al. [26] showed that the data reflecting the change in the crystal cell parameters of titanium dioxide due to the $\mathrm{C}$ and $\mathrm{N}$ co-doping at 400 and $500{ }^{\circ} \mathrm{C}$, respectively. During the cooling process, the specimen remained its position inside the furnace tube, and this process could take longer or shorter time due to different ambient temperatures. In this study, the ambient temperature was $16^{\circ} \mathrm{C}$ in an air-conditioned room. Natural cooling was used to allow the temperatures of the furnace and the heat-treated sample to reach the room temperature together. 


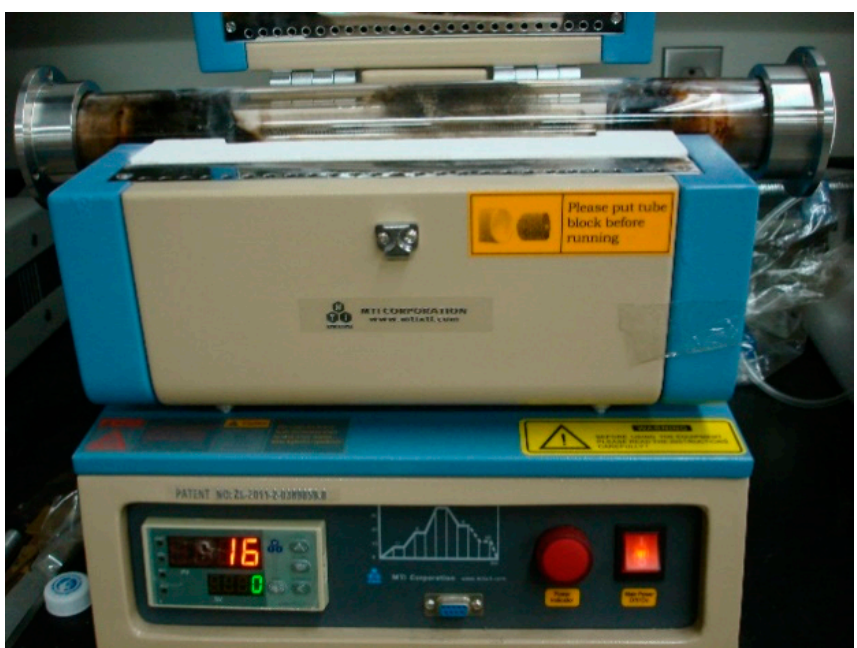

(a)

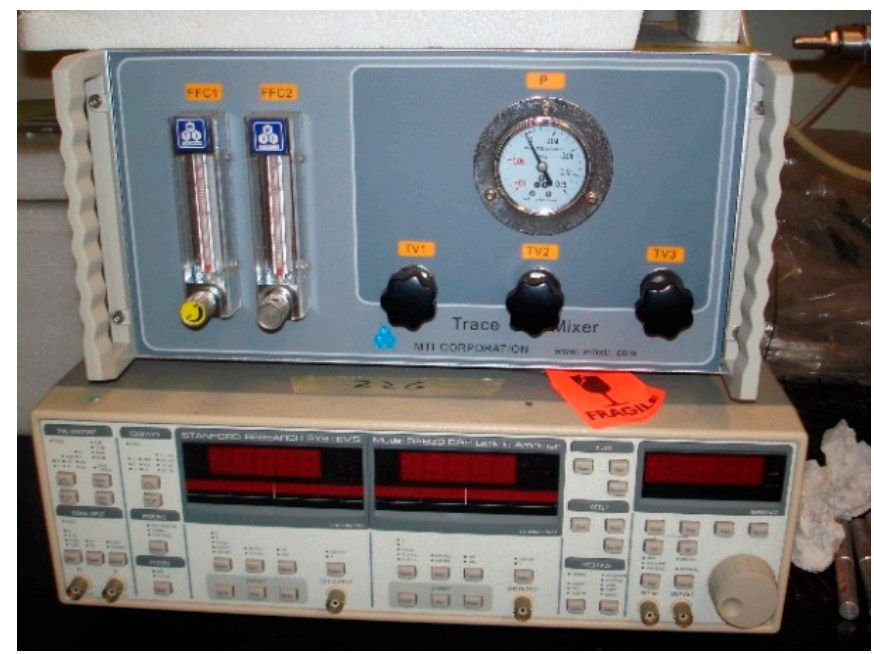

(b)

Figure 2. Photos showing the set-up for the fiber heat treatment: (a) split furnace with a quartz tube as the reaction chamber; (b) multi-channel gas-flow-controlling unit.

\subsection{Characterization}

A scanning electron microscope (SEM model: JEOL JSM-6010PLUS/LA) was used to examine the microstructure of the prepared composite fiber. A SONY DSC-W100 cyber-shot camera was used to take photos of the composite fiber before and after the heat treatment. Representative pictures were used to show the fiber specimens for spilled oil cleaning. The CHI440C electrochemical workstation was used to measure the open circuit voltages of the specimens with and without the cobalt addition under visible light excitation. During the photosensitivity test, the data requisition rate was set as 10 data per second.

\section{Results and Discussion}

\subsection{Morphology of the Composite Carbon Fiber}

The composite carbon fiber containing titanium oxide particles was examined by SEM. From Figure $3 a$, it can be seen that the oxide nanoparticles were embedded into the micro- and nanofibers. The nanoparticles were not in clusters. Instead, a pretty uniform distribution of the nanoparticles in the fibers can be found. Increasing the particle loading dosage was also studied. The concentration of the oxide-particle-forming precursors was an important parameter for affecting the final morphology of the materials prepared. In 
Figure $3 b$, the carbon fiber showed a significant change in the size. This indicted that the processing parameter could impact the morphology of the heat-treated fiber.

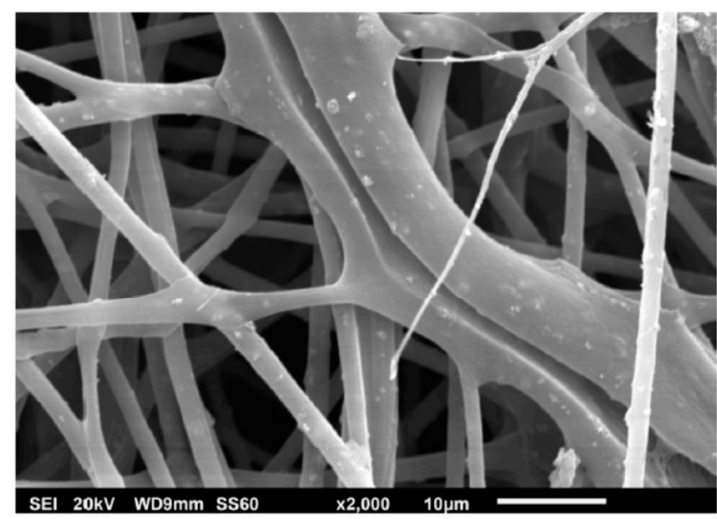

(a)

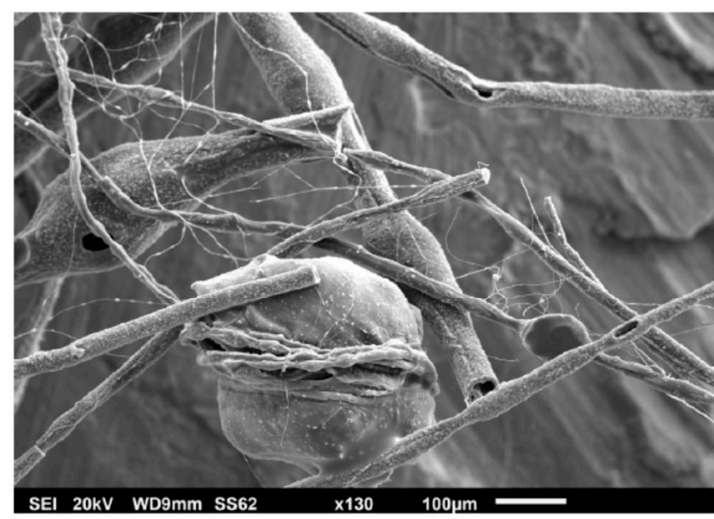

(b)

Figure 3. SEM images of oxide particles/fibers (a) and composite fibers (b) with different sizes.

\subsection{Photosensitivity of the Composite Carbon Fiber}

The photosensitivity tests on the titanium dioxide containing carbon fiber composites were performed. A fluorescent light tube was used to generate visible light. An Electrochemical Workstation (the Instrument model: CHI440C) was used to record the photon-voltage response data. The composite carbon fiber was placed on transparent glass slides, and aluminum foil strips were used to form electrically conductive paths. The light source was controlled as "On" for $5 \mathrm{~s}$ followed by "Off" for $5 \mathrm{~s}$. The test results were obtained and are shown in Figure 4. The open-circuit potential (the voltage between the test leads), $E$, versus time, $t$, curve as shown in Figure 4 a revealed that the fiber sample possessed an $n$-type semiconducting behavior. When the visible light bulb was switched to the "On" position, the light illumination caused the generation of electrons at the anode and the voltage became more negative. However, when the light was "Off", a positive surge of the voltage was found, as shown in Figure $4 \mathrm{a}$. Such an $n$-type behavior was associated with the addition of cobalt-doped titanium-based oxide particles in the carbonized fiber. If there was no cobalt addition, the photosensitivity was not so strong, as shown in Figure $4 \mathrm{~b}$. The photon-induced voltage at the anode was not so stable, which is also shown in Figure $4 \mathrm{~b}$ by the larger drift of the baseline.

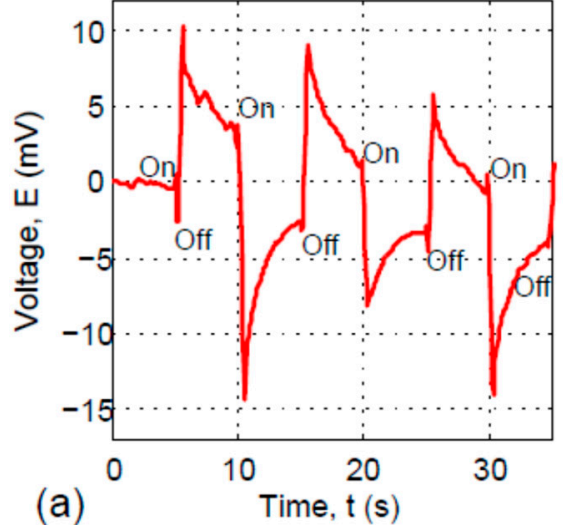

Figure 4. Open-circuit voltages of the cobalt(II) titanate particle-containing composite carbon fiber (a) and the titanium dioxide particle-containing composite carbon fiber (b).

To evaluate the dye cleaning effect of the composite nanofiber, a rhodamine B (RB) solution at a $0.1 \mathrm{mM}$ concentration was prepared and used in the absorption experiment. 
The $\mathrm{CoTiO}_{3}$ particles containing the composite carbon fiber sample was attached to a stainless-steel mesh to make a photoanode. The nominal area of the stainless-steel mesh was about $20 \times 20 \mathrm{~mm}$. The photoanode was immerged into the RB solution. A platinum wire with a diameter of $0.5 \mathrm{~mm}$ was used as the cathode. The distance between the platinum cathode and the composite nanofiber photoanode was kept at about $25 \mathrm{~mm}$. Under sunlight illumination, the RB in the solution was removed gradually. This was checked by using a spectrometer to measure the UV-VIS light absorbance of the RB. The intensity of the UV-VIS light varied, as shown by the results in Figure 5. Figure 5a shows the light absorbance of the $0.1 \mathrm{mM}$ RB solution without degradation. After six days, the UV-VIS absorbance of the solution was measured again, and the results are presented in Figure 5b. Comparing the results in Figure 5a and in Figure 5b, it was found that the absorbance was decreased. The absorbance band became narrower as well. This indicated the reduction in the impurity in the solution due to the adsorption and the removal of the $\mathrm{RB}$ by the composite carbon fiber sample. It must be pointed out that the adsorption and absorption of impurity by the fiber sample could remove the absorption spectrum below $500 \mathrm{~nm}$. The reasons for the difference in the light absorption level at $560 \mathrm{~nm}$ could be from both the adsorption/absorption and the photocatalytic effect generated by the composite carbon fiber.

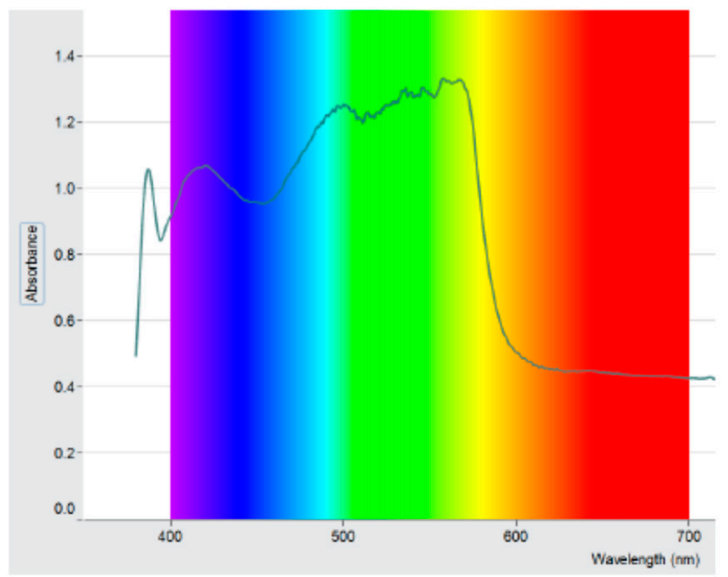

(a)

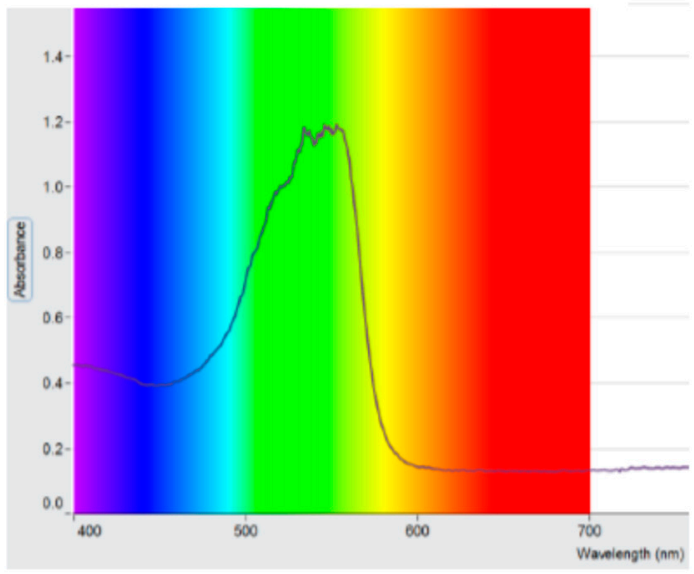

(b)

Figure 5. Absorbances of the $0.1 \mathrm{mM}$ rhodamine B (RB) solution before decomposition by the cobalt-titanate particle-containing composite fiber (a) and after decomposition for 6 days under sunlight (b).

As known, pure $\mathrm{TiO}_{2}$ with an anatase crystalline phase structure only shows photoactivity under the illumination of UV light with wavelengths $\lambda$ of $<387 \mathrm{~nm}$, because it has an energy band gap of $3.3 \mathrm{eV}$ [27]. Doped $\mathrm{TiO}_{2}$ with a high sensitivity to visible light $(\lambda>400 \mathrm{~nm})$ can harvest solar energy. Visible-light-sensitive $\mathrm{TiO}_{2}$ can be made by metal-ion doping [28] and nonmetal doping [29]. Doping $\mathrm{TiO}_{2}$ changes its crystal structure, tuning of band gap energy, as demonstrated by measurements using XRD [30], UV-VIS photoluminescence [31], XPS [32], and other techniques for example, Raman analysis [33]. In this work, the electrospinning followed by heat treatment caused the $\mathrm{TiO}_{2}$ particles doped with N, C, and Co. This would result in the change of the structure, band gap, and electrically conductive behavior.

To evaluate the spilled-oil cleaning performance of the nanofiber specimens, the removal of vegetable oil was conducted. The results for the absorption of vegetable oil are shown by Figure 6. The time-dependent wetting of oil in various samples was examined. Oil drops were set on the six specimens including two pieces of titanium foil strips (a pure titanium and a titanium with a nanotube surface coating), two nanofiber samples (the nanofiber before the heat treatment and the nanofiber after the heat treatment), and two glass slides as the control specimens. The oil absorption behaviors of the six tested 
materials varied with time. In both Figure $6 a, b$, the six specimens were arranged in the same sequences as follows. From the very top, it was the pure titanium sample. The pure titanium was followed by the heat-treated titanium dioxide nanotube specimen. Then counterclockwise, the white-color non-heat-treated titanium dioxide nanofiber sample can be found. The heat-treated cobalt(II) titanate nanofiber showed a pale green color. The rest of the specimens were clean glass slides. In Figure 6a, it can be seen that the oil spread the most across the heat-treated nanofiber specimen. Oil drops were absorbed instantly into the nanofibers. While on a clean glass, the oil drops remained intact. In Figure 6b, it is more apparently shown that the oil spread out the most for the heat-treated nanofiber sample, followed by the titanium nanotube sample, non-heat-treated titanium dioxide nanofiber sample, pure titanium, and last the clean glass.

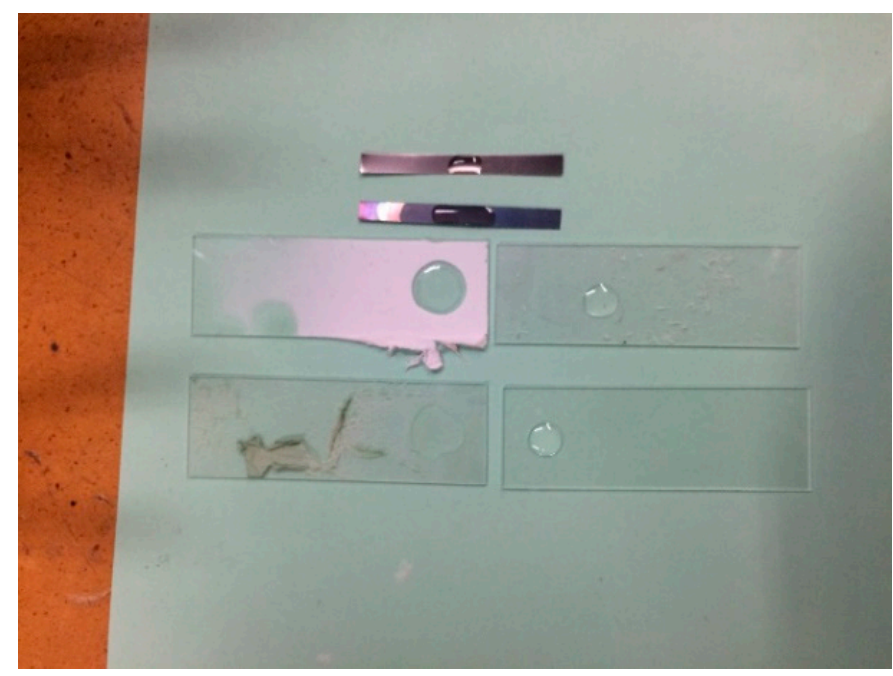

(a)

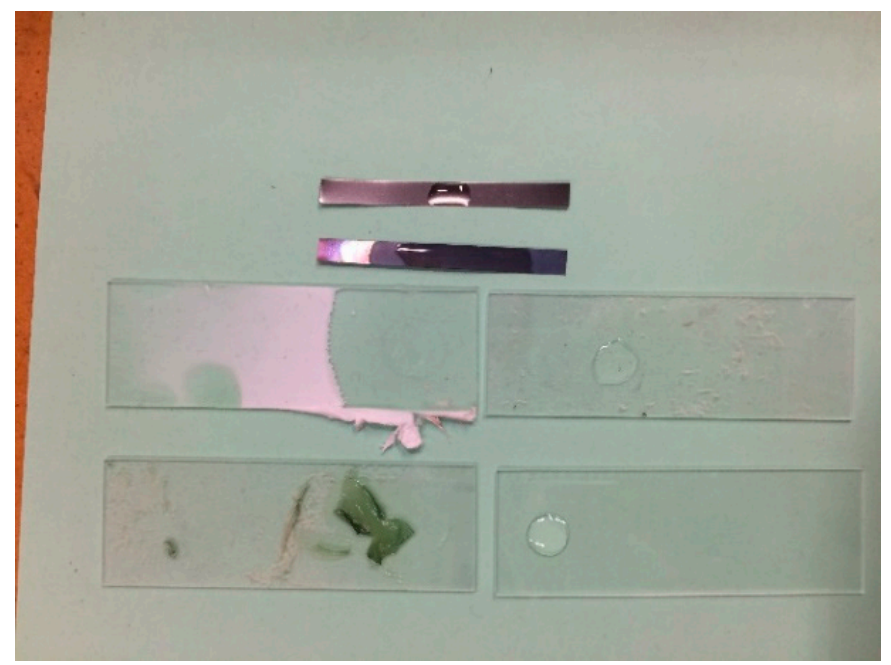

(b)

Figure 6. Photos of oil drops on glass slides after $10 \mathrm{~min}$ exposure to sunlight (a) and after $20 \mathrm{~min}$ exposure (b).

Based on the results shown by the above photos in Figure $6 \mathrm{a}, \mathrm{b}$, it was concluded that the titanium dioxide-containing fiber sample had a good oil absorption and cleaning ability. The fiber was also good at removing the oil. Out of the six test samples after each time measurement, the oil spread out the most for the fiber sample. This behavior is beneficial in cleaning the oil. It may also be used for biological disinfection, because titanium dioxide has been widely used as a disinfectant [34]. The composite carbon fiber was made not only 
for the initially proposed spilled-oil cleaning, but also as a raw material for the wearable technologies and micro- and nanorobots.

In Figure 7, two photographs taken using a SONY DSC-W100 digital camera are shown. As can be seen from the photos, two pieces of titanium metal oxide particle-loaded carbon fiber mats were placed on a piece of a blue-colored paper. The mats were made of the same cobalt(II) titanate particle-containing carbon fiber. The left side of the photo illustrated a water drop with a diameter of $8 \mathrm{~mm}$ staying on the composite carbon fiber mat without any wetting to the fiber. The right side of the picture shows that a spilled oil drop was instantly absorbed into the fiber wool and was gradually removed under sunlight. This revealed the hydrophobic and oleophilic behavior of the composite carbon fiber.

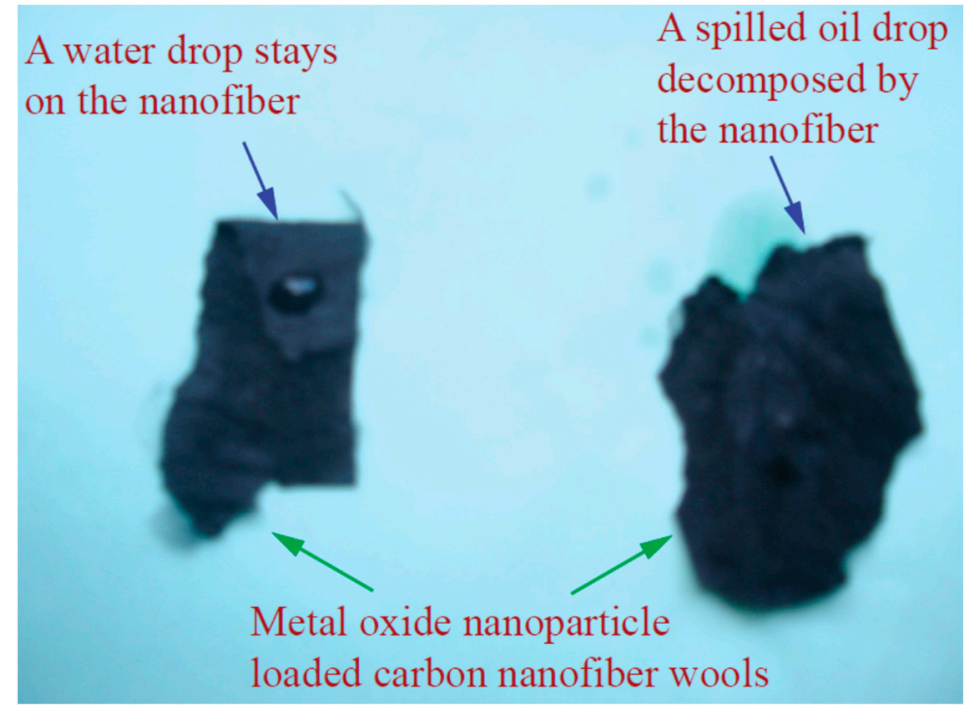

Figure 7. Photographs showing the hydrophobic and oleophilic behaviors of the composite carbon fiber.

The quantitative analysis of oil wetting was made by measuring the wetting angles. As shown in Figure 8a, a silicon oil for vacuum pump usage was dropped on a piece of a glass plate, and the wetting angle, $\theta$, was measured as $40^{\circ}$. When the same type of oil was dropped on the cobalt(II) titanate particle-containing composite carbon fiber mat, the oil was instantly absorbed by the fiber mat, as shown in Figure $8 \mathrm{~b}$. The accurate oil-to-fiber mat wetting angle, $\theta$, in this case was difficult to measure. However, it was estimated as $0^{\circ}$. The oil wetting test results further validated the oleophilic behavior of the composite carbon fiber.

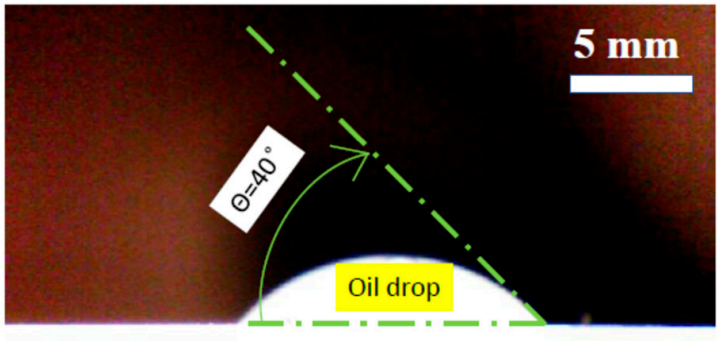

Glass plate

\section{Metal plate}

(a)

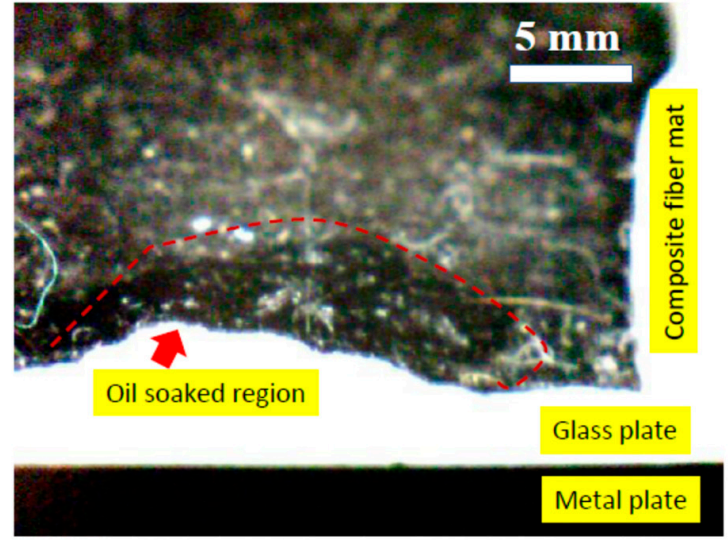

(b)

Figure 8. Images showing the contact of oil with a glass plate (a) and with a composite fiber mat (b). 
Similarly, the quantitative analysis of the water-to-fiber mat wetting behavior was performed by measuring the wetting angle variation vs. time. At the beginning of the test, a drop of water was set at the edge of the fiber mat, as shown in Figure 9a. The wetting angle, $\theta$, was measured as $138^{\circ}$. When the water drop was set about $60 \mathrm{~min}$ at the same location, the shape of the drop did not change much. Only the size was slightly reduced due to the evaporation of water. The wetting angle as shown in Figure $9 \mathrm{~b}$ was close to $135^{\circ}$. Obviously, the composite carbon fiber as a highly hydrophobic material was further confirmed.

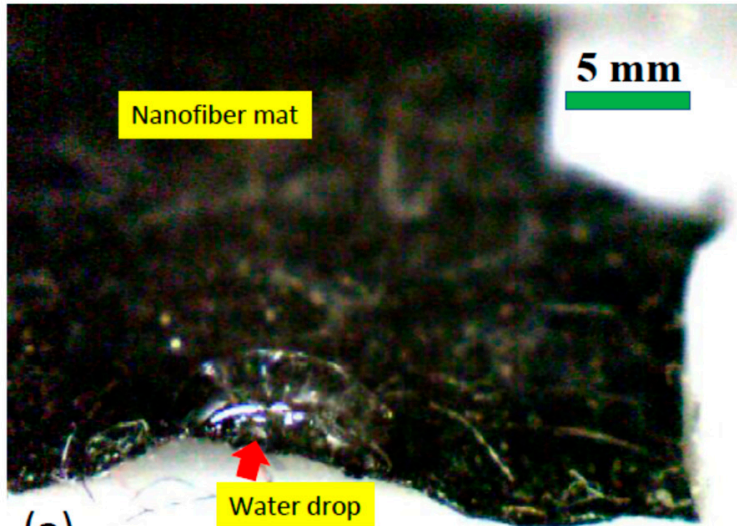

(a)

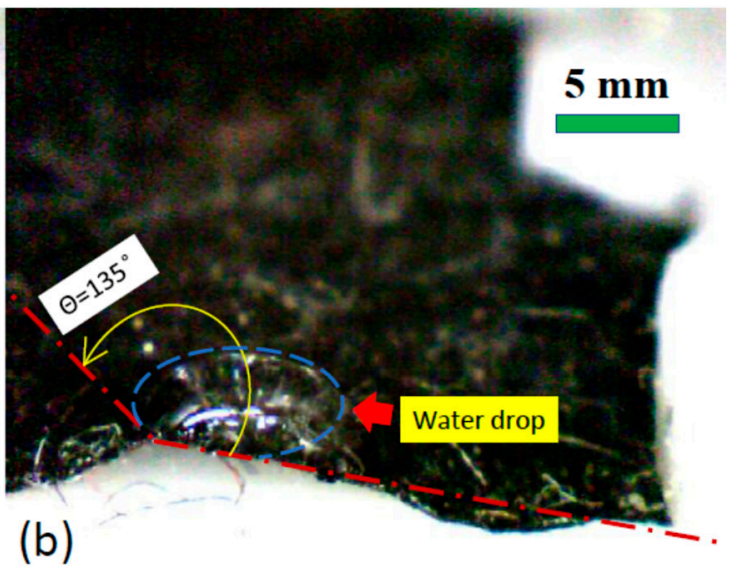

(b)

Figure 9. Images showing the contact between water and the composite carbon fiber: (a) water drop just setting at the edge of the fiber mat; (b) contact angle measured after $60 \mathrm{~min}$.

\section{Conclusions}

A functional composite carbon fiber with a large active surface area for spilled oil adsorption and cleaning was successfully prepared and tested. The composite carbon fiber consisted of oxide particles, and the carbon was generated from the polymer, PAN. The polymer as the continuous phase for holding the particle-generating substances was spun into composite fiber mats first and then carbonized at high temperatures in a protective atmosphere.

The cobalt(II) titanate particles-containing composite carbon fiber showed a photosensitive property. Co-electrospinning the polymer and oxide-generating substances was found to promote the uniform dispersion of the produced particles within the carbon fiber. The fiber also showed a demanded high surface area for oil absorption and cleaning. Specifically, titanium dioxide nanoparticles were prepared in situ through the hydrolysis of an organometallic compound in the electrospinning process. Cobalt(II) titanate particles were generated in situ during the high-temperature annealing in a protective atmosphere. The composite fiber mats showed the photosensitivity in the visible light spectrum. Due to the hydrophobic and oleophilic behaviors, the composite carbon fiber mats were effective in spilled oil absorption and cleaning.

Author Contributions: Conceptualization, Y.X.G., A.A. and J.Y.; methodology and validation, Y.X.G.; formal analysis, Y.X.G., A.A. and J.Y.; resources, Y.X.G.; writing-original draft preparation, Y.X.G.; writing-review and editing, A.A.; visualization, Y.X.G.; supervision, Y.X.G.; project administration, Y.X.G.; funding acquisition, Y.X.G. All authors have read and agreed to the published version of the manuscript.

Funding: This project is sponsored by the U.S. Department of Homeland Security (DHS) Summer Research Team (SRT) Program under contract number DE-SC0014664. We acknowledge the partial support from U.S. National Science Foundation (NSF) under Grant Number CMMI-1333044. The SEM images were made possible through the NSF MRI grant DMR-1429674.

Acknowledgments: "This research was performed under an appointment to the U.S. Department of Homeland Security (DHS) Science \& Technology (S\&T) Directorate Office of University Programs Summer Research Team Program for Minority Serving Institutions, administered by the Oak Ridge Institute for Science and Education (ORISE) through an interagency agreement between the U.S. 


\begin{abstract}
Department of Energy (DOE) and DHS. ORISE is managed by Oak Ridge Associated Universities (ORAU) under DOE contract number DE-SC0014664. All opinions expressed in this paper are the authors' and do not necessarily reflect the policies and views of DHS, DOE, or ORAU/ORISE". The support from the hosting site, Arctic Domain Awareness Center (ADAC) in Summer 2021, is gratefully acknowledged. The mentorship provided by the former Center Director, Randy "Church" Kee, and the former Principal Investigator of the Center, Professor Douglas Causey, is indispensable for the success of the 2021 summer research program. We also appreciate Elizabeth "Ellee" Matthews (ADAC Education \& Administrative Manager), Jason "Olaf" Roe (ADAC Associate Director), Beth White (DHS Education Program Manager), and Cedricka Harris (DHS Education Program Specialist) for their invaluable assistance. Anan Hamdan is appreciated for assisting us in performing the SEM imaging.
\end{abstract}

Conflicts of Interest: The authors declare no conflict of interest.

\title{
References
}

1. Agyei-Tuffour, B.; Gbogbo, S.; Dodoo-Arhin, D.; Damoah, L.N.W.; Efavi, J.K.; Yaya, A.; Nyankson, E. Photocatalytic degradation of fractionated crude oil: Potential application in oil spill remediation. Cogent Eng. 2020, 7, 1744944. [CrossRef]

2. Abdelghafour, M.M.; Deak, A.; Merai, L.; Agoston, A.; Belteki, R.; Sebok, D.; Dekany, I.; Janovak, L. Photocatalytic elimination of interfacial water pollutants by floatable photoreactive composite nanoparticles. Environ. Pollut. 2020, $266,115285$. [CrossRef] [PubMed]

3. Li, Z.K.; He, H.Q.; Liang, Y.; Ouyang, L.K.; Zhang, T.C.; Yuan, S.J. Photocatalytically driven self-cleaning and underwater superoleophobic copper mesh modified with hierarchical $\mathrm{Bi}_{2} \mathrm{WO}_{6} @ \mathrm{CuO}$ nanowires for oil/water separation. Ind. Eng. Chem. Res. 2020, 59, 16450-16461. [CrossRef]

4. Song, S.; Yang, H.; Zhou, C.L.; Cheng, J.; Jiang, Z.B.; Lu, Z.; Miao, J. Underwater superoleophobic mesh based on BiVO 4 nanoparticles with sunlight-driven self-cleaning property for oil/water separation. Chem. Eng. J. 2017, 320, 342-351. [CrossRef]

5. Wang, W.W.; Lin, J.X.; Cheng, J.Q.; Cui, Z.X.; Si, J.H.; Wang, Q.T.; Peng, X.F.; Turng, L.S. Dual super-amphiphilic modified cellulose acetate nanofiber membranes with highly efficient oil/water separation and excellent antifouling properties. J. Hazard. Mater. 2020, 385, 121582. [CrossRef]

6. Chu, Z.Z.; Li, Y.T.; Zhou, A.Q.; Zhang, L.; Zhang, X.C.; Yang, Y.; Yang, Z.H. Polydimethylsiloxane-decorated magnetic cellulose nanofiber composite for highly efficient oil-water separation. Carbohydr. Polym. 2022, 277, 118787. [CrossRef]

7. Pirzada, T.; Ashrafi, Z.; Xie, W.Y.; Khan, S.A. Cellulose silica hybrid nanofiber aerogels: From sol-gel electrospun nanofibers to multifunctional aerogels. Adv. Funct. Mater. 2020, 30, 1907359. [CrossRef]

8. Jeddi, M.K.; Laitinen, O.; Liimatainen, H. Magnetic superabsorbents based on nanocellulose aerobeads for selective removal of oils and organic solvents. Mater. Des. 2019, 183, 108115. [CrossRef]

9. Li, J.; Guan, P.; Li, M.J.; Zhang, Y.; Cheng, P.P.; Jia, R.A. Anticorrosive superhydrophobic polystyrene-coated mesh for continuous oil spill clean-up. New J. Chem. 2017, 41, 4862-4868. [CrossRef]

10. Parangusan, H.; Ponnamma, D.; Hassan, M.K.; Adham, S.; Al-Maadeed, M.A. Designing carbon nanotube-based oil absorbing membranes from gamma irradiated and electrospun polystyrene nanocomposites. Materials 2019, 12, 709. [CrossRef]

11. Zhou, K.H.; Liu, M.; Ye, X.M.; Zhu, Y.W.; Liu, Z.B.; Yang, Y.P.; Dan, Y.Q.; Yuan, Y.F.; Hou, H.L. Electrospun highly crystalline ZnO nanofibers: Super-efficient and stable photocatalytic hydrogen production activity. Chemistryselect 2019, 5, 6691-6696. [CrossRef]

12. Ge, H.N.; Xu, F.Y.; Cheng, B.; Yu, J.G.; Ho, W.K. S-Scheme heterojunction $\mathrm{TiO}_{2} / \mathrm{CdS}$ nanocomposite nanofiber as $\mathrm{H}_{2}$ production photocatalyst. Chem CatChem 2019, 11, 6301-6309. [CrossRef]

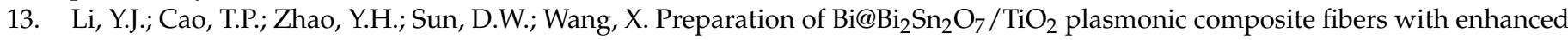
photocatalytic hydrogen generation activity. Chin. J. Inorg. Chem. 2019, 35, 1371-1378. [CrossRef]

14. Khalily, M.A.; Yurderi, M.; Haider, A.; Bulut, A.; Patil, B.; Zahmakiran, M.; Uyar, T. Atomic layer deposition of ruthenium nanoparticles on electrospun carbon nanofibers: A highly efficient nanocatalyst for the hydrolytic dehydrogenation of methylamine borane. ACS Appl. Mater. Interf. 2018, 10, 26162-26169. [CrossRef]

15. Yue, X.Z.; Yi, S.S.; Wang, R.W.; Zhang, Z.T.; Qiu, S.L. Well-controlled $\mathrm{SrTiO}_{3} @ \mathrm{Mo}_{2} \mathrm{C}$ core-shell nanofiber photocatalyst: Boosted photo-generated charge carriers transportation and enhanced catalytic performance for water reduction. Nano Energy 2018, 47, 463-473. [CrossRef]

16. Yang, L.P.; Wang, M.M.; Slattum, P.M.; Bunes, B.R.; Wang, Y.H.; Wang, C.Y.; Zang, L. Donor-acceptor supramolecular organic nanofibers as visible-light photoelectrocatalysts for hydrogen production. ACS Appl. Mater. Interf. 2018, 10, 19764-19772. [CrossRef]

17. Lee, J.J.; Noh, W.; Huh, T.H.; Kwark, Y.J.; Lee, T.S. Synthesis of conjugated microporous polymer and its embedding in porous nanofibers for visible-light-driven photocatalysis with reusability. Polymer 2020, 211, 123060. [CrossRef]

18. Khalil, A.; Aboamera, N.M.; Nasser, W.S.; Mahmoud, W.H.; Mohamed, G.G. Photodegradation of organic dyes by PAN/SiO ${ }_{2}-$ $\mathrm{TiO}_{2}-\mathrm{NH}_{2}$ nanofiber membrane under visible light. Separat. Purif. Technol. 2019, 224, 509-514. [CrossRef]

19. Homaeigohar, S.; Botcha, N.K.; Zarie, E.S.; Elbahri, M. Ups and downs of water photodecolorization by nanocomposite polymer nanofibers. Nanomaterials 2019, 9, 250. [CrossRef] 
20. Riaz, S.; Park, S.J. An overview of $\mathrm{TiO}_{2}$-based photocatalytic membrane reactors for water and wastewater treatments. J. Ind. Eng. Chem. 2020, 84, 23-41. [CrossRef]

21. Wu, M.C.; Liao, H.C.; Cho, Y.C.; Toth, G.; Chen, Y.F.; Su, W.F.; Kordas, K. Photo-Kelvin probe force microscopy for photocatalytic performance characterization of single filament of $\mathrm{TiO}_{2}$ nanofiber photocatalysts. J. Mater. Chem. A 2013, 1, 5715-5720. [CrossRef]

22. Wu, M.C.; Wu, P.Y.; Lin, T.H.; Lin, T.F. Photocatalytic performance of Cu-doped $\mathrm{TiO}_{2}$ nanofibers treated by the hydrothermal synthesis and air-thermal treatment. Appl. Surf. Sci. 2018, 430, 390-398. [CrossRef]

23. Yuan, L.; Wei, X.; Martinez, J.P.; Yu, C.; Panahi, N.; Gan, J.B.; Zhang, Y.; Gan, Y.X. Reaction spinning titanium dioxide particlecoated carbon fiber for photoelectric energy conversion. Fibers 2019, 7, 49. [CrossRef]

24. Wu, M.C.; Hiltunen, J.; Sapi, A.; Avila, A.; Larsson, W.; Liao, H.C.; Huuhtanen, M.; Toth, G.; Shchukarev, A.; Laufer, N.; et al. Nitrogen-doped anatase nanofibers decorated with noble metal nanoparticles for photocatalytic production of hydrogen. ACS Nano 2011, 5, 5025-5030. [CrossRef] [PubMed]

25. Meramo-Hurtado, S.; Ceballos-Arrieta, N.; Cortes-Caballero, J.; Leon-Pulido, J.; Gonzalez-Quiroga, A.; Gonzalez-Delgado, A.D Inherent safety assessment of industrial-scale production of chitosan microbeads modified with $\mathrm{TiO}_{2}$ nanoparticles. Biomolecules 2021, 11, 568. [CrossRef]

26. Chen, D.M.; Jiang, Z.Y.; Geng, J.Q.; Wang, Q.; Yang, D. Carbon and nitrogen co-doped TiO ${ }_{2}$ with enhanced visible-light photocatalytic activity. Ind. Eng. Chem. Res. 2007, 46, 2741-2746. [CrossRef]

27. Zaleska, A. Doped-TiO 2 : A review. Recent Pat. Eng. 2008, 2, 157-164. [CrossRef]

28. Choi, J.; Park, H.W.; Hoffmann, M.R. Effects of single metal-ion doping on the visible-light photoreactivity of TiO 2 . J. Phys. Chem. C 2010, 114, 783-792. [CrossRef]

29. Khedr, T.M.; El-Sheikh, S.M.; Hakki, A.; Ismail, A.A.; Badawy, W.A.; Bahnemann, D.W. Highly active non-metals doped mixed-phase $\mathrm{TiO}_{2}$ for photocatalytic oxidation of ibuprofen under visible light. J. Photochem. Photobiol. A Chem. 2017, 346, 530-540. [CrossRef]

30. Patil, S.B.; Basavarajappa, P.S.; Ganganagappa, N.; Jyothi, M.S.; Raghu, A.V.; Reddy, K.R. Recent advances in non-metals-doped $\mathrm{TiO}_{2}$ nanostructured photocatalysts for visible-light driven hydrogen production, $\mathrm{CO}_{2}$ reduction and air purification. Int. J. Hydrogen Energy 2019, 44, 13022-13039. [CrossRef]

31. Ilie, M.; Cojocaru, B.; Parvulescu, V.I.; Garcia, H. Improving $\mathrm{TiO}_{2}$ activity in photo-production of hydrogen from sugar industry wastewaters. Int. J. Hydrogen Energy 2011, 36, 15509-15518. [CrossRef]

32. Sathish, M.; Viswanathan, B.; Viswanath, R.P.; Gopinath, C.S. Activity of nitrogen-doped $\mathrm{TiO}_{2}$ nanocatalyst. Chem. Mater. 2005, 17, 6349-6353. [CrossRef]

33. Thambiliyagodage, $\mathrm{C}$. Activity enhanced $\mathrm{TiO}_{2}$ nanomaterials for photodegradation of dyes-A review. Environ. Nanotechnol. Monit. Manag. 2021, 16, 100592. [CrossRef]

34. Kühn, K.P.; Chaberny, I.F.; Massholder, K.; Stickler, M.; Benz, V.W.; Sonntag, H.G.; Erdinger, L. Disinfection of surfaces by photocatalytic oxidation with titanium dioxide and UVA light. Chemosphere 2003, 53, 71-77. [CrossRef] 